\title{
Microglial nodules in early multiple sclerosis white matter are associated with degenerating axons
}

\author{
Shailender Singh $\cdot$ Imke Metz $\cdot$ Sandra Amor $\cdot$ Paul van der Valk $\cdot$ \\ Christine Stadelmann • Wolfgang Brück
}

Received: 12 September 2012/Revised: 10 January 2013/ Accepted: 13 January 2013/Published online: 26 January 2013

(C) The Author(s) 2013. This article is published with open access at Springerlink.com

\begin{abstract}
Microglial nodules in the normal-appearing white matter have been suggested as the earliest stage(s) of multiple sclerosis (MS) lesion formation. Such nodules are characterized by an absence of leukocyte infiltration, astrogliosis or demyelination, and may develop into active demyelinating MS lesions. Although the etiology of MS is still not known, inflammation and autoimmunity are considered to be the central components of this disease. Previous studies provide evidence that Wallerian degeneration, occurring as a consequence of structural damage in MS lesions, might be responsible for observed pathological abnormalities in connected normal-appearing white matter. As innate immune cells, microglia/macrophages are the first to react to even minor pathological changes in the CNS. Biopsy tissue from 27 MS patients and autopsy and biopsy tissue from 22 normal and pathological controls were analyzed to determine the incidence of microglial nodules. We assessed MS periplaque white matter tissue from early disease stages to determine whether microglial
\end{abstract}

Electronic supplementary material The online version of this article (doi:10.1007/s00401-013-1082-0) contains supplementary material, which is available to authorized users.

S. Singh · I. Metz · C. Stadelmann · W. Brück $(\bowtie)$

Department of Neuropathology, University Medical Center,

Georg-August University Göttingen, Robert-Koch-Str. 40,

37075 Göttingen, Germany

e-mail:wbrueck@med.uni-goettingen.de

S. Singh $\cdot$ S. Amor $\cdot$ P. van der Valk

Department of Pathology, VU University Medical Center,

Amsterdam, The Netherlands

\section{S. Amor}

Neuroscience and Trauma Centre, Barts and the London School of Medicine and Dentistry, Queen Mary University of London, London, UK nodules are associated with altered axons. With immunohistochemical methods, the spatial relation of the two phenomena was visualized using HLA-DR antibody for MHC II expression by activated microglia/macrophages and by applying antibodies against damaged axons, i.e., SMI32 (non-phosphorylated neurofilaments) and amyloid precursor protein as well as neuropeptide $\mathrm{Y}$ receptor $\mathrm{Y} 1$, which marks axons undergoing Wallerian degeneration. Our data demonstrate that the occurrence of microglial nodules is not specific to MS and is associated with degenerating as well as damaged axons in early MS. In addition, we show that early MS microglial nodules exhibit both pro- and antiinflammatory phenotypes.

Keywords Wallerian degeneration - Microglial nodules · Multiple sclerosis - Preactive lesions · Axonal damage . Microglia activation

\section{Introduction}

Multiple sclerosis (MS) is a chronic inflammatory CNS disease characterized by multifocal inflammation, extensive demyelination, gliosis and axonal damage. The etiology of MS is still not known, and the first cellular events in the MS brain remain to be clarified. Microglia are the resident immune cells that react to even minor pathological events in the CNS [27], and microglial activation might arguably be considered an initial pathogenetic event in MS. Inflammation and microglia/macrophage activation may cause myelin/axonal damage or, alternatively, the cells may scavenge damaged myelin/axonal debris. A cluster of activated microglia/macrophages is commonly termed a 'microglial nodule' without a strict definition of the cell number. Studies of post-mortem MS brain tissues 
have proposed that microglia nodules observed in the socalled normal-appearing white matter (NAWM) may represent the earliest stage(s) in MS lesion development and were therefore called (p)reactive lesions $[13,46,52,55]$. Such nodules are identified in the absence of leukocyte infiltration, astrogliosis or demyelination [53, 55]. Microglial nodules are a well-known phenomenon in viral encephalitis, in which perineuronal aggregation of activated microglia/macrophages indicative of neuronal phagocytosis is often observed. Furthermore, phagocytosis of neuroaxonal debris by activated microglia/macrophages is in agreement with prior observations in MS [25]. In fact, activated microglia/macrophages also release a wide range of cytotoxins, free radicals, neurotrophic factors and immunomodulatory molecules, which may reflect immunoregulatory rather than just proinflammatory activity $[8,23]$. Two extremes of these activation states are classically activated (M1) and alternatively activated (M2) macrophages.

Axonal transection within the lesion, causing anterograde degeneration of the distal part of the axon-also known as Wallerian degeneration-might occur diffusely in the tissue surrounding the lesion, inducing microglial/ macrophage reaction to absorb axonal and myelin fragments in non-demyelinated MS white matter. Moreover, results of several neuropathological and neuroradiological studies confirmed Wallerian degeneration in early MS NAWM [10, 11, 18, 21, 48]. Based on MS periplaque white matter (PPWM) biopsy tissue, a recent study using an antibody against the neuropeptide Y receptor Y1 (NPYY1R) also showed widespread Wallerian degeneration [19]. The antigen detected by the anti-NPY-Y1R antibody remains to be determined. It is however known that peripheral nerve injury induces increased NPY expression in dorsal root ganglion neurons in rodents, and receptor $\mathrm{Y} 1$ is upregulated in neurons $[12,57,58,61]$. Thus, it is possible that NPY-Y1R plays a role in promoting survival during degenerative processes.

The main aim of our study was to investigate white matter biopsy tissue from early stage MS patients in order to determine whether axonal alterations are present in microglial nodules. To do so, we used anti-HLA-DR (an antigen belonging to human leukocyte-associated antigens class II) antibody for activated microglia/macrophages and three different immunohistochemical markers for damaged axons, i.e., SMI32, which reacts to damaged axons with non-phosphorylated neurofilaments; amyloid precursor protein (APP) as a marker for transport disturbance in acutely damaged axons; and NPY-Y1R for axons undergoing Wallerian degeneration. Subsequently, we characterized the immune phenotype of MS microglial nodules using M1 and M2 macrophage markers. Based on the literature, we selected antibodies directed against CD40 and inducible nitric oxide synthase (iNOS) as M1 markers and mannose receptor and CD163 as M2 markers [3, 5, 23, $26,62]$. A better understanding of pathological processes in non-demyelinated white matter in early MS may enable prevention of further damage in the CNS through rational therapeutic strategies.

\section{Materials and methods}

\section{Patients}

We investigated biopsy tissue from 27 patients who had been diagnosed with inflammatory demyelination of the CNS consistent with MS. A total of 44 tissue blocks, which included non-demyelinated white matter regions, were used for the study. The biopsies were performed in different neurosurgery centers for various diagnostic reasons, for example, to exclude neoplastic or infectious diseases. Informed consent had been obtained from each patient. None of the study authors was involved in decision making with respect to biopsy. However, histology showed inflammatory demyelinating lesions typical for MS. Specimens were sent to the Department of Neuropathology in Göttingen, Germany, for a second opinion. Patients received the diagnosis of MS according to the McDonald's or Poser's criteria [36, 43]. Of the 27 patients, 8 underwent comprehensive clinical follow-up: 6 patients (MS nos. 3, 4, $7,13,19,25)$ had a relapsing-remitting course, MS no. 11 showed all the characteristics of primary progressive MS [51], and MS no. 27 entered a secondary progressive disease course years after biopsy. All the other 19 patients were diagnosed with clinically isolated syndrome suggestive of MS. Patient characteristics are summarized in Supplement 1.

We also analyzed archival paraffin-embedded brain tissue obtained from seven brain infarct (four autopsy and three biopsy) cases, three traumatic brain injury (TBI) autopsies, and seven biopsies from patients who underwent surgery for temporal lobe epilepsy. The control group consisted of autopsy CNS tissue from five patients who died suddenly because of non-neurological disorders. No neurological abnormalities were found in any routine autopsy control cases; in particular, there were no signs of inflammation, hypoxia or neuronal damage. The interval between death and autopsy ranged from 24 to $48 \mathrm{~h}$ (median $=24 \mathrm{~h})$ in infarct, 10 to $24 \mathrm{~h}($ median $=22 \mathrm{~h})$ in TBI and 8 to $120 \mathrm{~h}$ (median $=72 \mathrm{~h}$ ) in control cases.

The study was carried out according to the national ethics guidelines and legal regulations regarding the use of archival post-mortem material. All patients and controls, or their next of kin, had given informed consent for autopsy. 
Histopathology

Specimens were fixed in $4 \%$ paraformaldehyde and embedded in paraffin. Sections $4 \mu \mathrm{m}$ thick were stained with hematoxylin and eosin (HE), luxol fast blue (LFB)/ periodic acid-Schiff (PAS) or Bielschowsky's silver impregnation. Immunohistochemical staining was performed with a biotin-avidin or an alkaline phosphatase/ anti-alkaline phosphatase technique. The primary antibodies used for diagnostic purposes were: anti-myelin basic protein (anti-MBP, rabbit polyclonal, DakoCytomation, Glostrup, Denmark), anti-proteolipid protein (anti-PLP, mouse monoclonal, Biozol, Eching, Germany), anti-myelin oligodendrocyte glycoprotein (anti-MOG, rat monoclonal, kindly provided by Prof. Linington, University of Glasgow, UK), anti-myelin-associated glycoprotein (anti-MAG, rabbit polyclonal, kindly provided by Prof. Schwab, University of Zürich, Switzerland), anti-cyclic nucleotide phosphodiesterase (anti-CNPase, mouse monoclonal, Covance Inc., Princeton, NJ, USA), KiM1P (macrophages, mouse monoclonal, kindly provided by Prof. Radzun, University of Göttingen, Germany) and antiMRP14 (activated macrophages, mouse monoclonal, BMA Biomedicals, Augst, Switzerland), anti-CD3 (T cells, rat monoclonal, Serotec, UK), anti-CD8 (cytotoxic T cells, rabbit polyclonal, Dako, Denmark), anti-glial fibrillary acidic protein (anti-GFAP, rabbit polyclonal, Dako, Denmark), anti-IgG (plasma cells, rabbit polyclonal, Dako, Denmark) and anti-complement C9neo antigen (anti-C9 neo, rabbit polyclonal, kindly provided by Prof. Morgan, University of Cardiff, UK). In order to detect damaged axons, we used anti-non-phosphorylated neurofilaments (SMI32, mouse monoclonal, Sternberger MD, USA) and anti-amyloid precursor protein (anti-APP, mouse monoclonal, Millipore, MA, USA). Wallerian degeneration was visualized using anti-neuropeptide-Y1 receptor (anti-NPYY1R, rabbit polyclonal, Acris Antibodies, Hiddenhausen, Germany). PPWM in all the 44 tissue blocks demonstrated normal myelin staining with the above-mentioned myelin markers. The occurrence of microglial nodules was assessed by anti-HLA-DR (MHC II, mouse monoclonal, clone LN3, eBioscience, USA) (Fig. 1). All the detected microglial nodules and their surroundings were thoroughly investigated to verify the absence of leukocyte infiltration and astrogliosis on sequential tissue sections (data not shown). Immunohistochemistry was performed on MS biopsy tissue to detect expression of pro- and antiinflammatory markers in microglial nodules using antibodies against CD40 (anti-CD40, rabbit polyclonal, Acris Antibodies, Hiddenhausen, Germany), inducible nitric oxide synthase (anti-iNOS, rabbit polyclonal, Millipore, MA, USA), mannose receptor (anti-mannan binding protein, mouse monoclonal, Serotec, UK) and CD163 (anti-CD163, mouse monoclonal, Novo Laboratories, UK). Omission of primary antibody served as a control staining.

The antibody against NPY-Y1R used in this study stains degenerating nerve fibers and has been investigated in epilepsy, brain infarct and MS tissue previously [19, 42]. However, the antigen detected by this antibody in degenerating axons remains unknown. In the present study, we have further analyzed Wallerian degeneration in the axial dimension of MS PPWM biopsy tissue sections using a Z-stack module of confocal laser scanning microscopy. For fluorescent staining, sections containing microglial nodules were double-stained for HLA-DR and NPY-Y1R. Cy3labeled goat anti-mouse and Alexa 488-labeled goat antirabbit were used as secondary antibodies.

\section{Classification of multiple sclerosis lesions}

All biopsy specimens fulfilled the generally accepted criteria for the pathological diagnosis of MS, showing an inflammatory demyelinating lesion [31, 44]. Lesions were classified according to their demyelinating activity as described in detail earlier [9]. Early active lesions were infiltrated by numerous macrophages that are immunoreactive with major and minor myelin proteins (MBP, PLP, MAG, MOG, CNP). In late active lesion areas, degradation of myelin proteins was more advanced, and macrophages contained only MBP- (and PLP-) but not MOG- (or MAG-) positive myelin debris. Inactive lesions were completely demyelinated, and macrophages no longer contained myelin protein-positive degradation products within their cytoplasm. In early remyelinating plaques, thin, irregularly formed myelin sheaths were seen as well as a pronounced infiltration by macrophages/microglial cells and $\mathrm{T}$ cells. Remyelination was more advanced in late remyelinating lesions, and only a few inflammatory cells could be found.

Image analysis and experimental details

Tissue sections were analyzed using an Olympus BX51 fluorescence microscope equipped with a DP71 CCD camera (Olympus Optical Co, Ltd., Hamburg, Germany) and a Zeiss Cell Observer microscope with an AxioCam ICc 3 CCD camera (Carl Zeiss MicroImaging, Ltd., Göttingen, Germany) or by confocal laser scanning microscopy with a Fluoview 1000 Olympus microscope. All the images were prepared in Adobe Photoshop CS4, version 11.0.2. The numbers of cells constituting microglial nodules were counted as visualized on HLA-DR stained sections using light microscopy. For measuring the distances on tissue section, the analySIS ${ }^{\circledR}$ image processing software was used. Evaluation of damaged axons associated with microglial nodules was done by measuring the distance between the nearest $\mathrm{APP}^{+} / \mathrm{SMI}^{2} 2^{+}$axonal structure and nodule- 

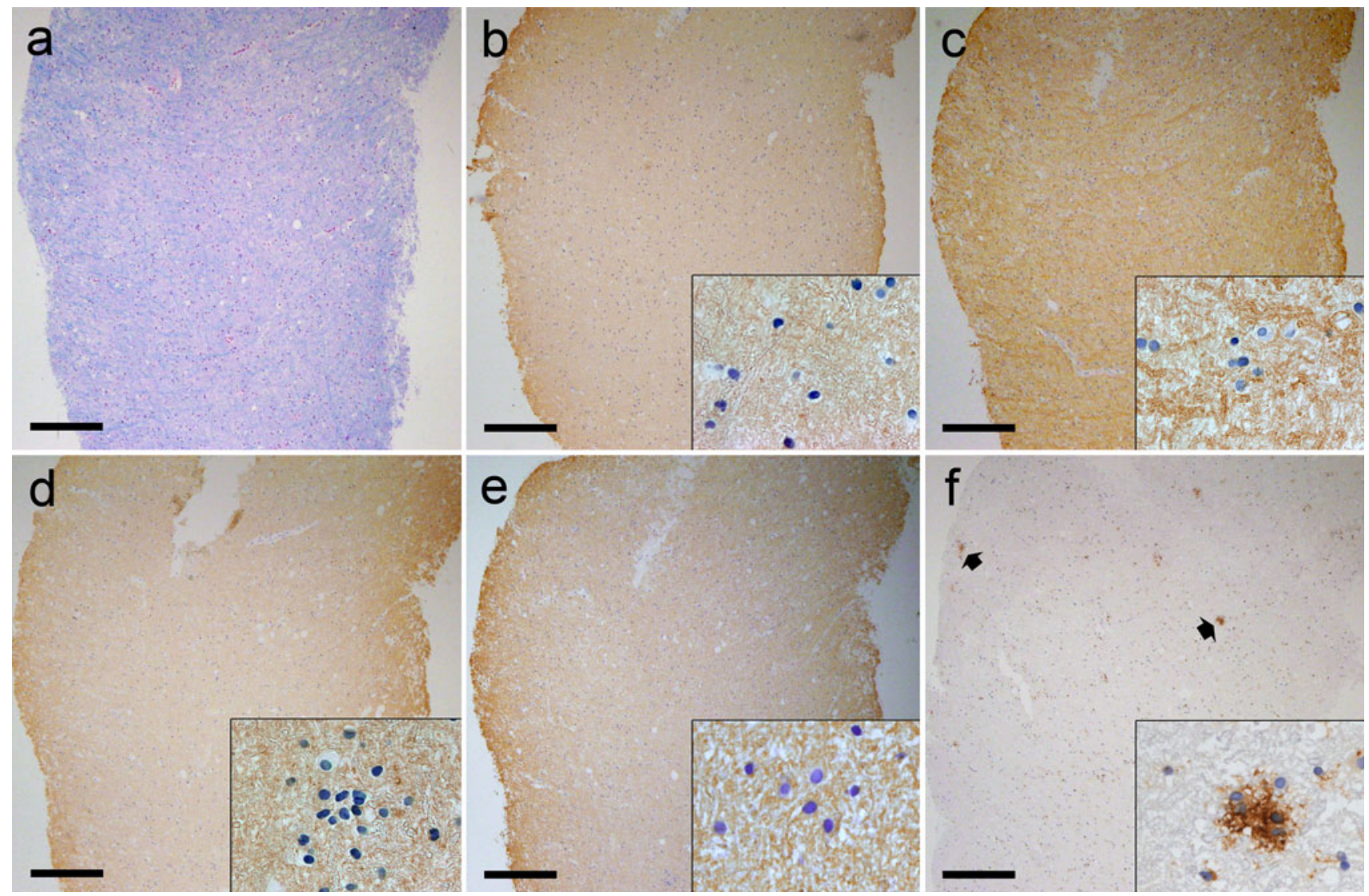

Fig. 1 Microglial nodules are found in the normally myelinated periplaque white matter in MS biopsy tissue. Staining for LFB/PAS (a) and immunohistochemistry for PLP (b), MBP (c), MOG (d) and MAG (e) on sequential tissue sections showed normal myelin (MS no.

forming nuclei. Three-dimensional reconstruction from confocal Z-stack images was performed using Imaris Bitplane scientific software, version 7.5.

\section{Statistical analysis}

Differences in the number of microglial nodules against lesion activity were statistically analyzed by Mann-Whitney $U$ test. Statistical analysis for the group difference between microglial nodules containing APP-positive axonal profiles and microglial nodules lacking APP-positive axonal profiles was performed using non-parametric $t$ tests. Statistical significance was defined as $p<0.05$.

\section{Results}

Incidence of microglia nodules in white matter from patients with early stage MS

To screen for microglial nodules, we examined PPWM tissue from 27 biopsied MS patients with a median interval

7). Activated microglia/macrophages and circumscribed nodules (arrows) that express HLA-DR are shown in (f). Insets in (b, c, d, e, f) show higher magnification of the respective tissue immunostaining. Scale bars $=(\mathbf{a}-\mathbf{f}) 250 \mu \mathrm{m}$

from symptom onset to biopsy of 22.5 days (range, 3 days11 years). Identification of microglial nodules in the tissue blocks containing PPWM was based on sequential immunohistochemical staining of tissue sections for MHC II (HLA-DR) and myelin markers, i.e., LFB/PAS, PLP, MBP, MOG and MAG (Fig. 1). Microglial nodules (HLA-DR ${ }^{+}$) showing variable morphologies, composed of four or more cells, were observed in 16 patients $(59.3 \%)$ and 20 blocks $(45.5 \%)$. The median number of cells constituting microglial nodules was 9 cells per nodule and ranged from 4 to 18 cells per nodule. The median time to biopsy was 21 days (range, 3-44 days) for the patients containing microglial nodule(s). We observed that the microglial nodules in PPWM occurred more frequently in patients with early active and late active lesions compared to patients with inactive lesions (Table 1). However, the quantitative determination of microglial nodules against lesion activity revealed that microglial nodules in PPWM occur irrespective of the plaque activity. There was no significant difference in the number of nodules associated with early active as compared to late and inactive lesions $(p=0.11)$; similarly, no significant difference was found 
in the number of nodules associated with active demyelinating (i.e., both early and late active) lesions compared to inactive lesions $(p=0.45)$. Nonetheless, we cannot exclude the possibility that the studied PPWM region containing microglial nodules could also be in the proximity of other lesions not included in the studied tissue specimens. In addition, the shortest possible distances between microglial nodules and the nearest blood vessel present in the tissue sections were measured; the median distance was calculated at $541.76 \mu \mathrm{m}$ (range $81.47-1,554.75$ ). We further investigated nodule-forming microglia/macrophages using the antiMRP14 antibody. Monocytes express MRP14 early in their activation phase and during tissue invasion until their terminal differentiation to macrophages, but none of the microglial nodules or the surrounding microglia/macrophage cells were found to be MRP14-positive on sequentially stained tissue sections (data not shown) [9].

Microglial nodules are associated with damaged axons in early MS

Sequential tissue sections of PPWM were immunostained for HLA-DR and axonal damage markers, i.e., APP and SMI32. Intra-axonal APP accumulation representing disturbed axonal transport was observed along with terminal ovoids resembling small bulbs, whereas SMI32 stained morphologically intact axons as well as axons with alternating constrictions or single swellings as dot-like ovoids. Analysis of sequential tissue sections revealed that microglial nodules and surrounding activated microglia/ macrophages were associated with damaged axons (Fig. 2). All 48 microglial nodules studied were found to be associated with $\mathrm{SMI}_{3} 2^{+}$axons, while $\mathrm{APP}^{+}$axons and ovoids were detected in more than half of the studied nodules (Table 2). $\mathrm{APP}^{+} / \mathrm{SMI}^{2} 2^{+}$axonal structures were detected at a median distance of $4.22 \mu \mathrm{m}$ (range 2.97-5.68) from the nuclei of microglial nodules, which were considered to be associated with damaged axons. A non-parametric $t$ test was performed to evaluate occurrence of microglial nodules with $\mathrm{APP}^{+}$axonal structures; there was no significant difference in the number of APP-positive and APP-negative nodules $(p=0.37)$.

Simultaneous detection of microglial nodules and axons undergoing Wallerian degeneration

To investigate the relationship between microglial nodules and the process of Wallerian degeneration, double-labeled (i.e., HLA-DR and NPY-Y1R antibodies) immunostained sections from nine cases (MS nos. 1, 3, 4, 5, 7, 9, 11, 13, 14)
Table 1 Microglial nodule occurrence versus lesion activity

\begin{tabular}{|c|c|c|c|}
\hline MS no. & $\begin{array}{l}\text { No. of microglial } \\
\text { nodule(s) }\end{array}$ & $\begin{array}{l}\text { Lesion } \\
\text { activity }\end{array}$ & Source \\
\hline 1 & 3 & Inactive & Left parietal \\
\hline 2 & 3 & Inactive & Right frontal \\
\hline 3 & 2 & Late active & Right occipital \\
\hline 4 & 7 & Early active & Corpus callosum \\
\hline 5 & 1 & Late active & Right frontal \\
\hline 6 & 9 & Inactive & Left occipital \\
\hline 7 & 3 & Early active & Right occipital \\
\hline 8 & 1 & Early active & Right frontal \\
\hline 9 & 4 & Inactive & Right frontal \\
\hline 10 & 1 & Early active & Left temporal \\
\hline 11 & 1 & Late active & Right parietal \\
\hline 12 & 4 & Inactive & Left parietal \\
\hline 13 & 5 & Inactive & Left temporal \\
\hline 14 & 1 & Late active & Left frontal \\
\hline 15 & 2 & Early active & Left occipital \\
\hline 16 & 1 & Inactive & Right frontal \\
\hline 17 & Not present & Inactive & Right frontal \\
\hline 18 & Not present & Inactive & Occipital \\
\hline 19 & Not present & Inactive & Right frontal \\
\hline 20 & Not present & Inactive & Right temporal \\
\hline 21 & Not present & Inactive & Right frontal \\
\hline 22 & Not present & Inactive & Right occipital \\
\hline 23 & Not present & Inactive & Left temporal \\
\hline 24 & Not present & Late active & Left frontal \\
\hline 25 & Not present & Inactive & Left frontal \\
\hline 26 & Not present & Late active & Right frontal \\
\hline 27 & Not present & Inactive & Left frontal \\
\hline
\end{tabular}

were visualized using the confocal laser-scanning microscopy technique. All the $27 \mathrm{HLA}^{-\mathrm{DR}^{+}}$nodules from examined cases were found to be associated with NPY-Y1R ${ }^{+}$ structures (Table 2). The nodules were closely apposed to and sometimes clustering around degenerating axons as well as the activated, nodule-free microglia/macrophage cells (Fig. 3). A direct spatial association was observed between microglial nodules and axons undergoing Wallerian degeneration (Fig. 4). The presence of NPY-Y1R ${ }^{+}$fragments in nodule-forming $\mathrm{HLA}^{-\mathrm{DR}^{+}}$microglia/macrophage cells clearly underlines the functional relationship between degenerating axons and microglial/macrophage reaction (Fig. 5). This association is further visualized in Supplement 2. Quite intriguingly, not all NPY-Y1R ${ }^{+}$profiles were surrounded by HLA-DR ${ }^{+}$cells, which might indicate axonal degeneration is primary to microglia/macrophage activation of the type seen in microglial nodules [47]. 


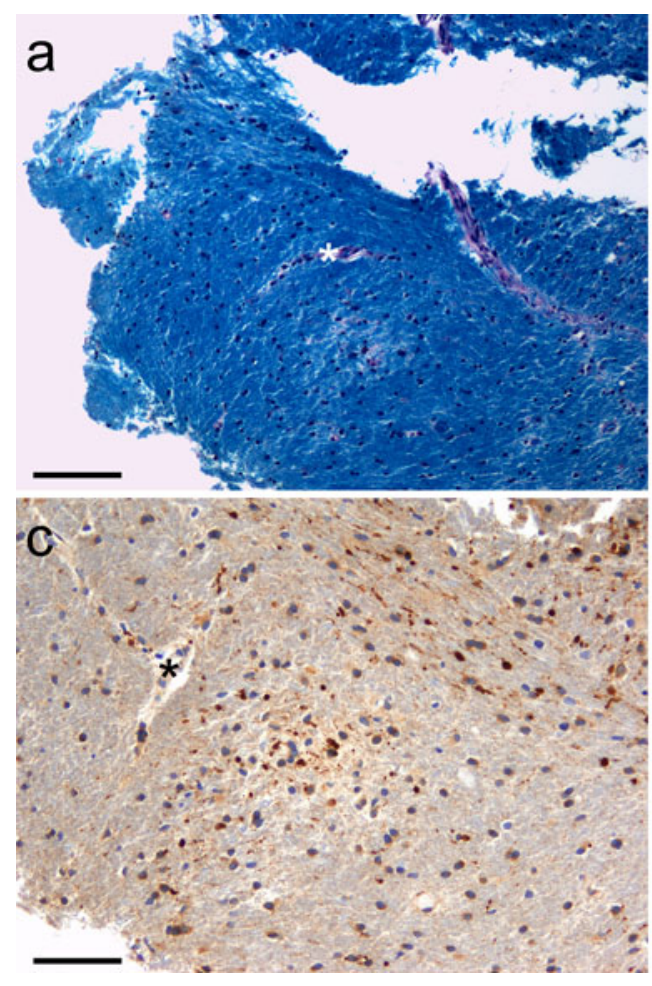

Fig. 2 Microglial nodules are associated with underlying axonal pathology in early multiple sclerosis. LFB/PAS stain and HLA-DR immunohistochemistry were used to identify microglial nodules in PPWM (a, b). Sequential tissue sections $(\mathbf{a}, \mathbf{b}, \mathbf{c}, \mathbf{d})$ were matched using a blood vessel (asterisk) (MS no. 5). The region of interest exhibits intact myelin (a). Microglial nodule representing cluster of activated HLA-DR expressing microglia/macrophages localized in

Table 2 Microglial nodules examined for damaged axons

Total number of nodules examined: 48

Nodules associated with $\mathrm{APP}^{+}$axons (\%): 29 out of 48 (60.42\%)

Nodules associated with SMI32 ${ }^{+}$axons (\%): 48 out of 48 (100\%)

Nodules associated with NPY-Y1R ${ }^{+}$axons (\%): 27 out of 27 $(100 \%)$

Microglial nodules are not specific to MS

To gain more insight into the prevalence of microglial nodules, we systematically screened autopsy and biopsy tissue from other neurological diseases (OND). Further details of OND, i.e., infarct, TBI, epilepsy and control cases, are summarized in Table 3. H\&E, LFB/PAS and HLA-DR staining was used to identify the nodules in normal white matter tissue. The occurrence of microglial nodules was observed in two TBI and all the seven infarct patients, whereas nodules were absent in epilepsy and non-neurological control patients. TBI and infarct lesions were characterized by strong macrophage infiltration and profound axonal loss and axonal spheroids; we found

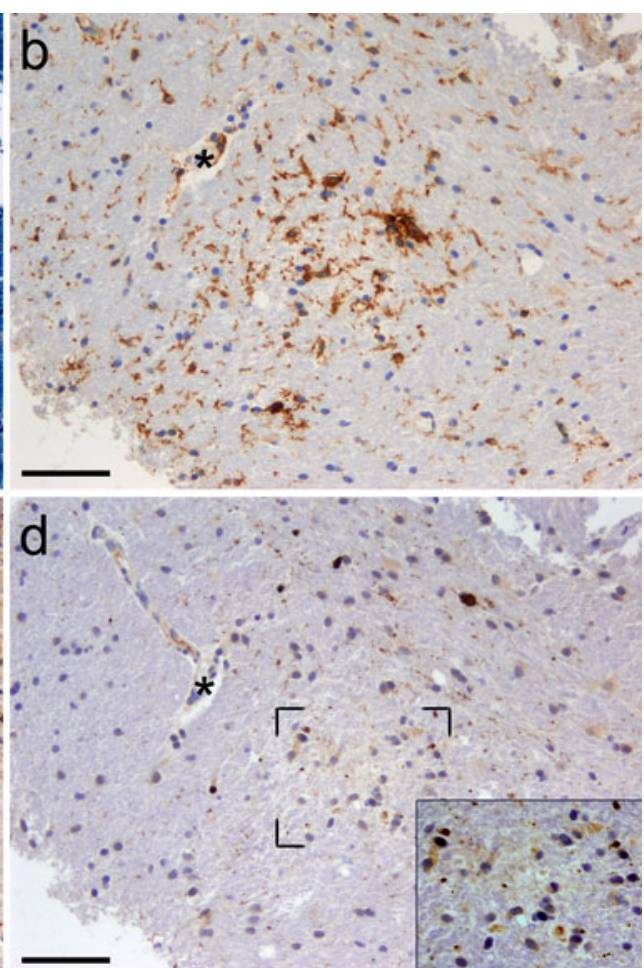

normally myelinated PPWM tissue (b). Sequential section identified injured/damaged axons associated with microglial nodules $(\mathbf{c}, \mathbf{d})$. $\mathrm{APP}^{+}$, acutely damaged axons are detected in close association with the microglial nodule (c). SMI32 ${ }^{+}$, axonal ovoids occur in the same region (d and inset). Inset in (d) shows higher magnification of the marked region. Scale bars $=$ (a) $100 \mu \mathrm{m}$; (b-d) $50 \mu \mathrm{m}$

abundant microglial nodules in the affected adjacent normal white matter (Fig. 6a-d). In patients who underwent surgery because of epilepsy, neuropathological examination revealed no significant abnormalities except for mild astrogliosis in two cases. Only a modest level of microglia/macrophage activation was present in the white matter; activated microglia/macrophages were almost evenly dispersed, and no microglial/macrophage clustering was observed in any of the epilepsy patients (Fig. 6e) [7].

Expression of M1 and M2 markers in activated microglia/macrophages and microglial nodules in MS

To determine the immune phenotype of microglial nodules in MS, we analyzed the expression of pro- and antiinflammatory markers characteristic for M1 and M2 macrophages. Microglia/macrophages associated with microglial nodules express both pro- and antiinflammatory markers (Fig. 7). Evaluation was performed on five cases (MS nos. 3, 6, 8, 13, 15) using antibodies against various surface proteins involved in antigen presentation and recognition, i.e., CD40, 


\section{HLA-DR / NPY-Y1R / DAPI}

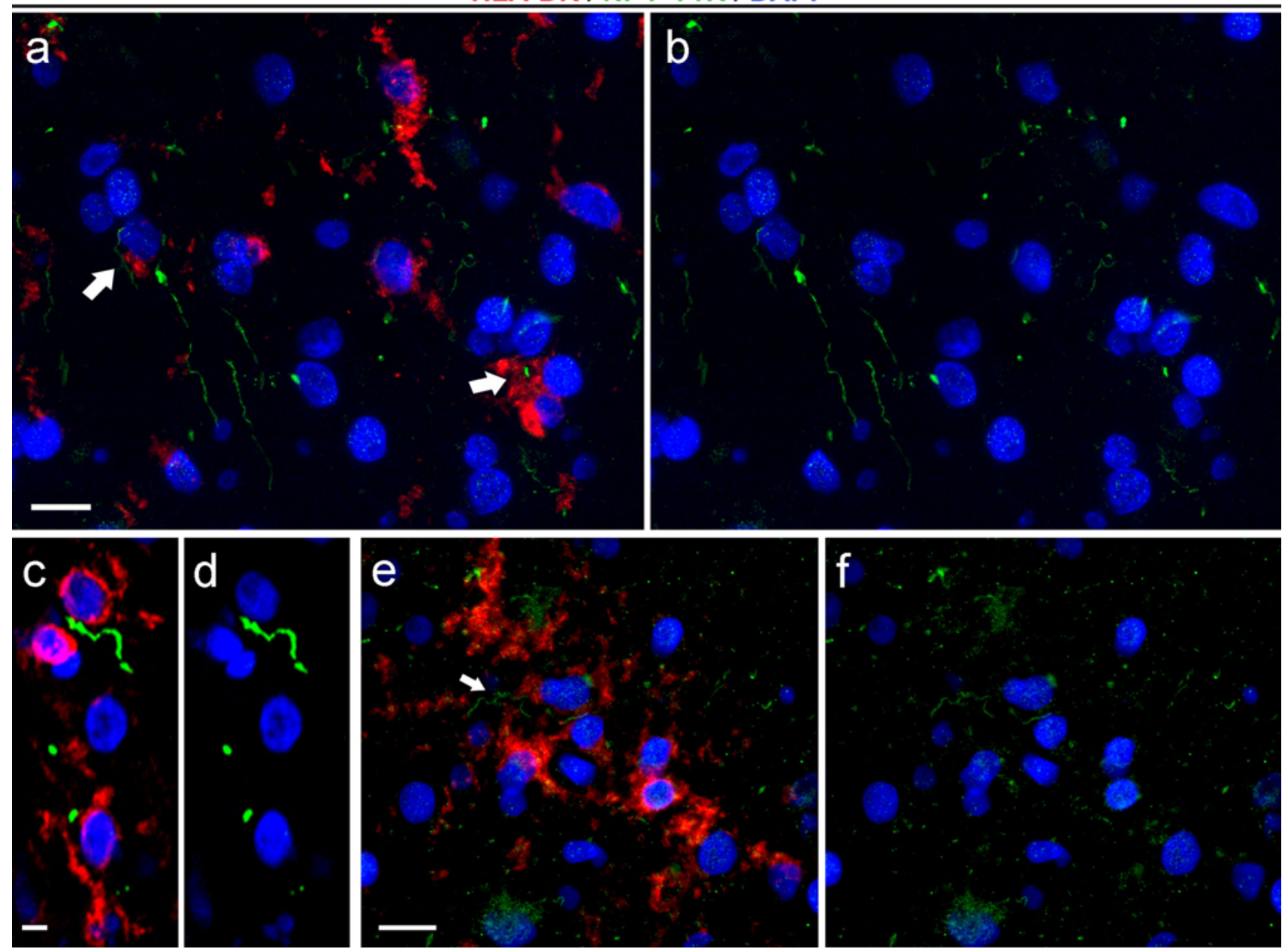

Fig. 3 Axons undergoing Wallerian degeneration in close spatial association with activated microglia/macrophages in MS PPWM. NPY-Y1R ${ }^{+}$axons (green) undergoing Wallerian degeneration apposed to HLA-DR ${ }^{+}$microglia/macrophages (red) with an activated morphology (arrows, a-b) (MS no. 14). NPY-Y1R ${ }^{+}$axons were frequently surrounded by activated microglia/macrophages throughout the PPWM (c-d) (MS no. 1). Activated microglia/macrophage cells were visualized clustering along the length of the NPY-Y1R ${ }^{+}$axonal segment (arrow, e-f) (MS no. 4). Stainings are merged with DAPI, which stains the nuclei $(\mathbf{a}-\mathbf{f}$, blue $)$. Scale bars $=(\mathbf{a}-\mathbf{b}) 25 \mu \mathrm{m} ;(\mathbf{c}-$ d) $10 \mu \mathrm{m} ;(\mathbf{e}-\mathbf{f}) 20 \mu \mathrm{m}$
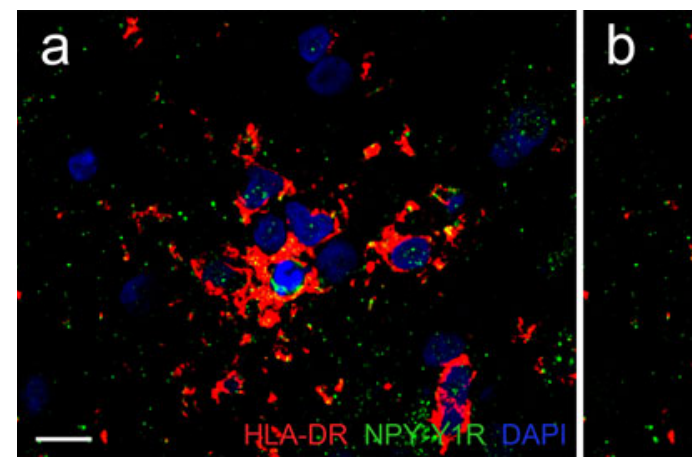

Fig. 4 Degenerating axons undergoing Wallerian degeneration associated with microglial nodule in MS. Fluorescent immunohistochemical staining for HLA-DR ( red) counterstained with DAPI (blue) shows a microglial nodule consisting of several microglial/macrophage cells (MS

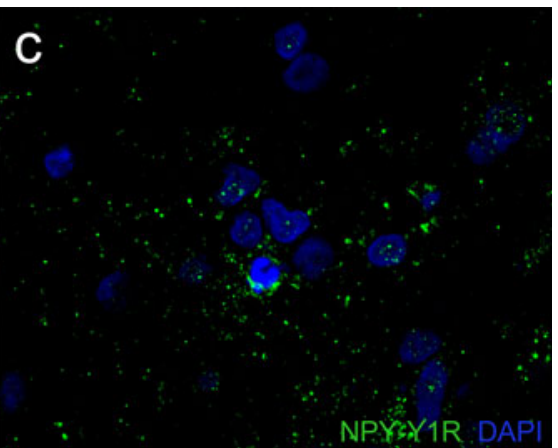

no. 11). The association of NPY-Y1R ${ }^{+}$fragments (green) with the microglial nodule suggests Wallerian degeneration induced formation of microglial nodule. Scale bar $=30 \mu \mathrm{m}$ 
Fig. 5 Intracellular NPY-Y1R ${ }^{+}$ axonal fragments in a HLA$\mathrm{DR}^{+}$nodule-forming microglial/macrophage cell. Nuclei of nodule-forming microglia/macrophage cells (blue, a), NPY-Y1R ${ }^{+}$particles $($ green, $\mathbf{b})$ present within the microglial/macrophage cytoplasm (red, c). The merge is shown in (d). The presence of intracellular NPY-Y1R ${ }^{+}$ fragments (arrow) in noduleforming HLA-DR ${ }^{+}$cell indicates engulfment of axonal debris by activated microglia/ macrophages. Scale bar $=15 \mu \mathrm{m}$

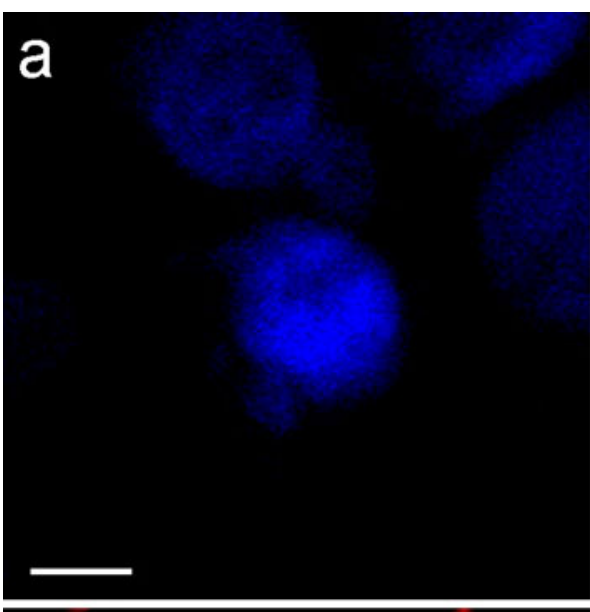

\section{b}
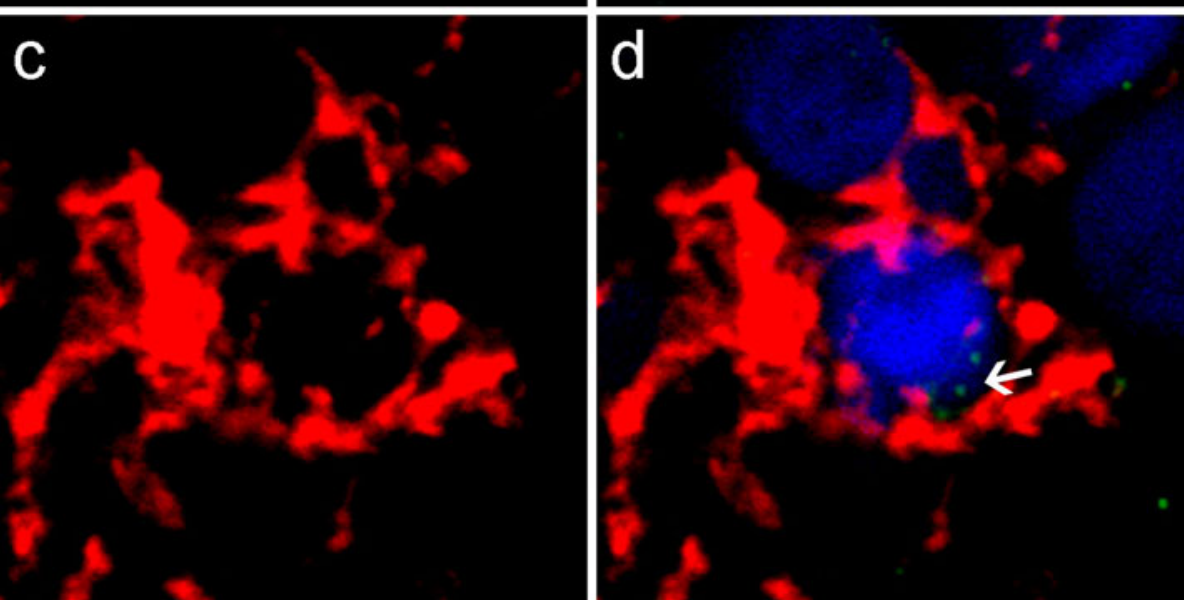

Table 3 Characteristics of OND and control cases

\begin{tabular}{|c|c|c|c|c|c|c|}
\hline \multirow{2}{*}{ Infarct } & \multirow[t]{2}{*}{ No. of cases } & \multirow[t]{2}{*}{ Median age (years) } & \multirow[t]{2}{*}{$\mathrm{F} / \mathrm{M}$ ratio } & \multicolumn{2}{|c|}{ Total no. of samples studied ${ }^{a}$} & \multirow[t]{2}{*}{$\begin{array}{l}\text { No. of patients with } \\
\text { microglial nodule(s) }\end{array}$} \\
\hline & & & & & & \\
\hline Autopsy & 4 & 59.5 (range, 43-86) & $1 / 3$ & 4 & & 4 \\
\hline Biopsy & 3 & 62 (range, 49-72) & $0 / 3$ & 5 & & 3 \\
\hline \multicolumn{7}{|l|}{ TBI } \\
\hline Autopsy & 3 & 44 (range, 18-47) & $0 / 3$ & 3 & & 2 \\
\hline \multicolumn{7}{|l|}{ Epilepsy } \\
\hline Biopsy & 7 & 39 (range, 28-48) & $3 / 4$ & 11 & & - \\
\hline Normal controls & Underlying disease & Cause of death & Age (years) & Sex & No. of samples studied ${ }^{a}$ & Microglial nodule(s) \\
\hline 1 & None & Multi-organ failure & 51 & M & 2 & - \\
\hline 2 & None & Aortic dissection & 71 & M & 3 & - \\
\hline 3 & Unknown & Acute cardiac failure & 64 & $\mathrm{~F}$ & 2 & - \\
\hline 4 & CAD & Acute cardiac failure & 58 & $\mathrm{~F}$ & 1 & - \\
\hline 5 & Unknown & Acute cardiac failure & 37 & F & 1 & - \\
\hline
\end{tabular}

$C A D$ coronary artery disease

- no nodules detected in the any of the samples

a Only white matter region(s) present in each sample were studied

iNOS, mannose receptor and CD163. CD40 and iNOS, proinflammatory molecules, were highly expressed throughout the MS PPWM and frequently observed in microglial nodules and activated microglia/macrophage clusters. CD163, a marker for antiinflammatory M2 macrophages, primarily stained perivascular macrophages but 

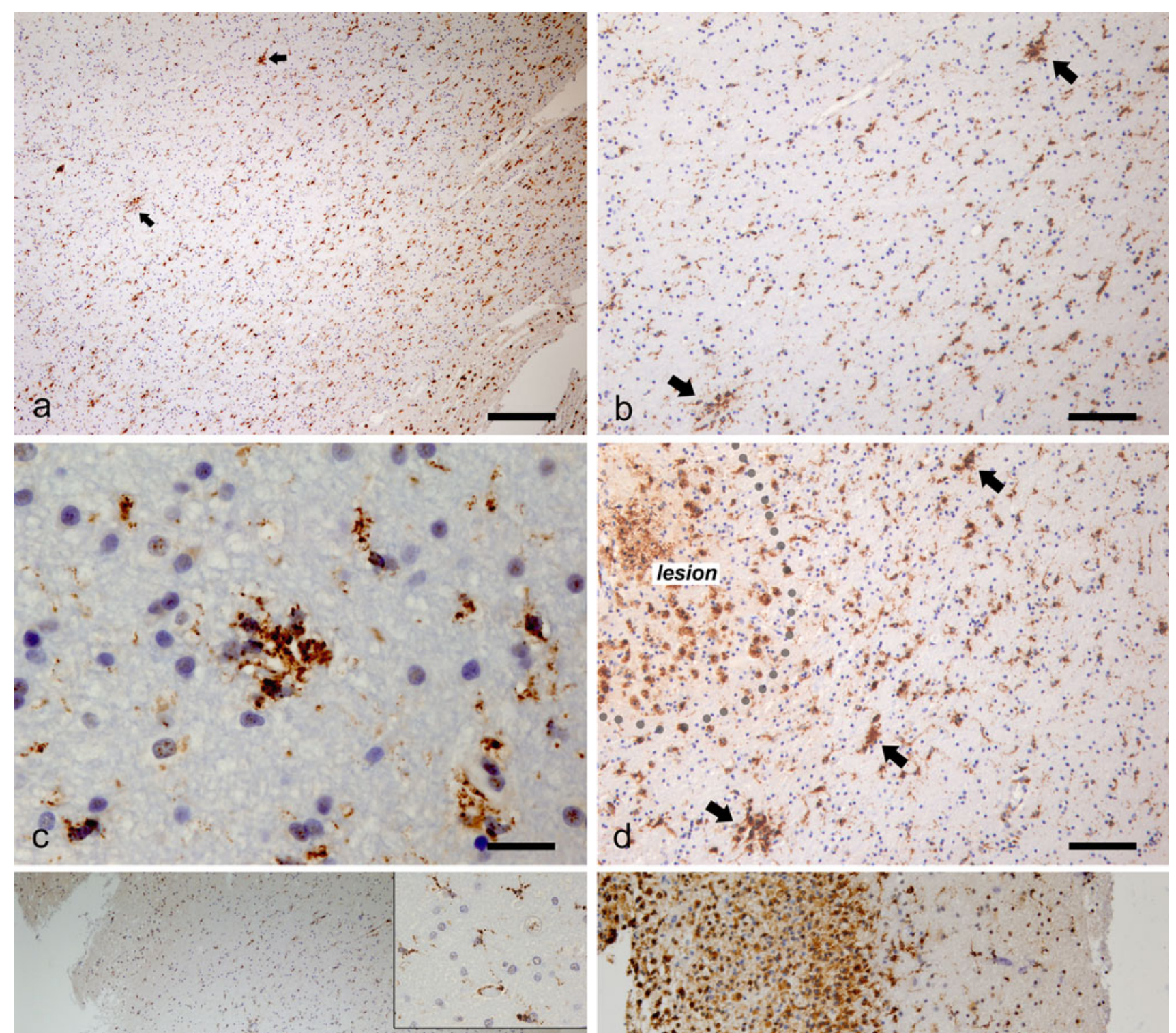

e

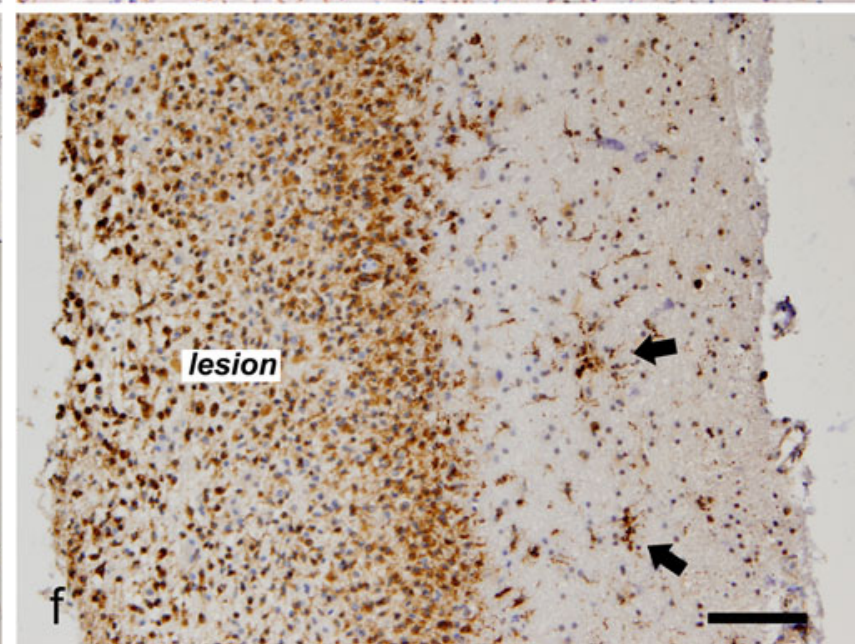

Fig. 6 Identification of microglial nodules in OND and MS. Microglia/macrophage activation (HLA-DR ${ }^{+}$) throughout the perilesional white matter in the autopsy tissue from an infarct case (a). b Represents a magnification of the region containing nodules in (a). Microglial nodule in the white matter biopsy tissue from a patient with cerebral infarction (c). White matter region surrounding

was also present in parenchymal PPWM microglia/macrophages in two cases (MS nos. 8 and 13). In contrast, the immunoreactivity of mannose receptor was mostly limited contusional lesion in an autopsy case (d). Disperse microglial/ macrophage activation in biopsied epilepsy white matter (e, inset). Nodules present adjacent to the biopsied MS lesion in MS no. 3 (f). Immunohistochemistry for HLA-DR: (a-f). Arrows: nodules. Scale bars $=(\mathbf{a}, \mathbf{e}) 250 \mu \mathrm{m} ;(\mathbf{b}, \mathbf{d}, \mathbf{f}) 100 \mu \mathrm{m} ;(\mathbf{c}) 25 \mu \mathrm{m}$

to perivascular macrophages and was only occasionally positive for parenchymal microglia/macrophages in PPWM regions. 

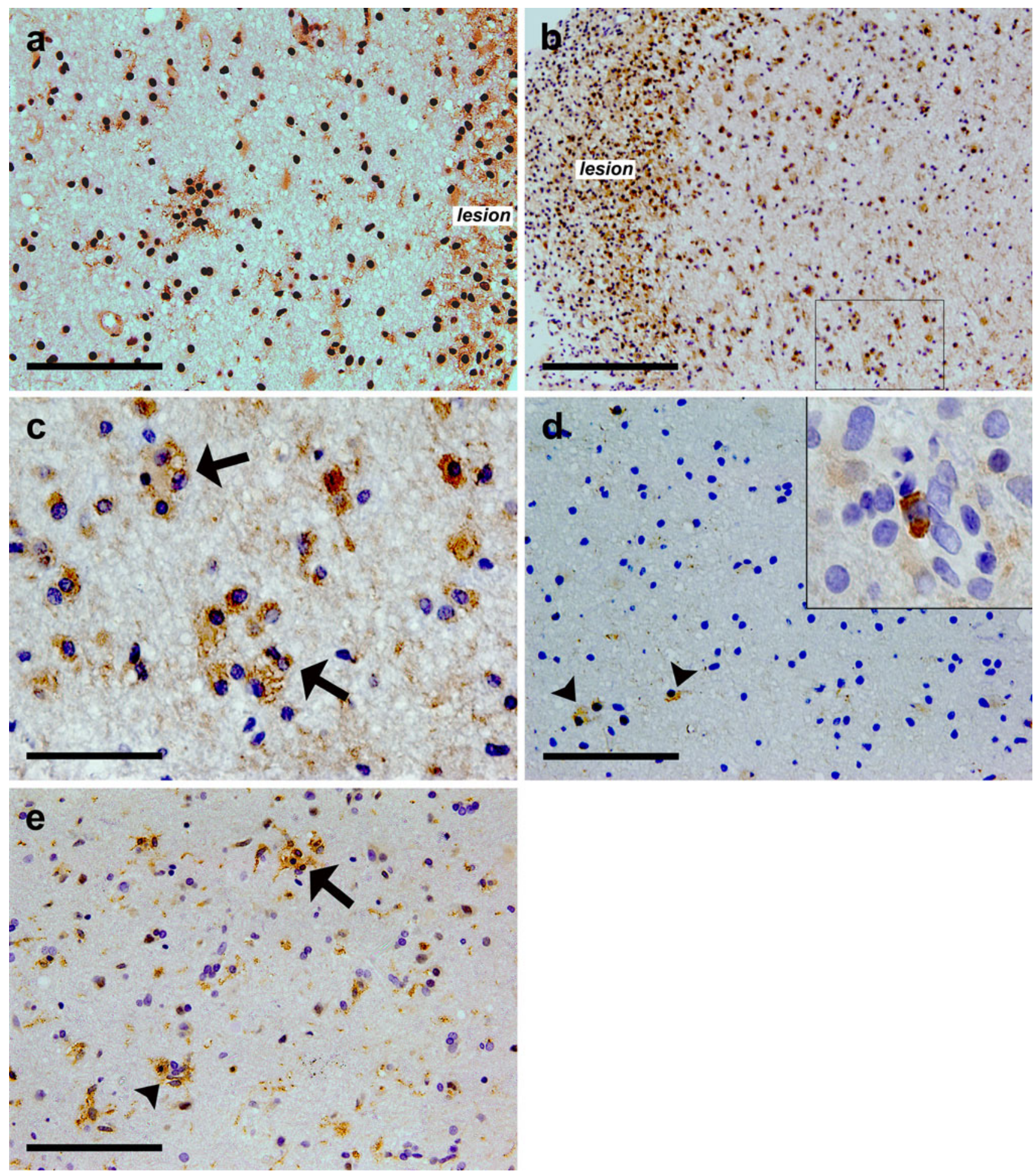

Fig. 7 Microglial nodules in MS display both classically (M1) and alternatively (M2) activated macrophage markers. CD40 was expressed in cells associated with microglial nodules present in PPWM (a) (MS no. 13). iNOS was present in phagocytes in demyelinating MS lesions and very frequently found to be expressed in the clusters forming a small foci of microglial/macrophage cells (arrows) in PPWM (b, c) (MS no. 6). c Represents a higher

magnification of the PPWM region marked with black box in (b). M2 marker mannose receptor was present perivascularly (inset of $\mathbf{d}$ ) and was only rarely expressed on parenchymal cells (arrowheads) in PPWM (d) (MS no. 13). CD163 was detected in activated microglia/ macrophages and microglial nodules (arrow) as well as in perivascular spaces (arrowhead) (d) (MS no. 8). Scale bars $=(\mathbf{a}, \mathbf{d}, \mathbf{e})$ $100 \mu \mathrm{m}$; (b) $200 \mu \mathrm{m}$; (c) $50 \mu \mathrm{m}$ 


\section{Discussion}

Our present study shows that microglial nodules are associated with damaged axons in early MS PPWM. Intraaxonal APP accumulation and changes of neurofilament phosphorylation served as a markers for axonal damage. Axons undergoing Wallerian degeneration showed granular degeneration and were detected using the anti-NPYY1R antibody. Here, we sought to clarify that microglial nodule formation is reactive in early MS white matter.

Over the last 2 decades, microglial nodules have been frequently noted in MS pathology. Prineas and colleagues $[1,45]$ detected deposits of activated complement (C3d) in elongated microglial nodules in MS PPWM, which suggests complement-mediated clustering of activated microglia/macrophages. Another study illustrated the role of oligodendrocyte stress in microglial nodules, although the ultimate cause of this abnormality remains unclear [55]. However, oligodendrocytes exist in close relationship with axons; thus, stressed axons might very well serve as an initiating source. These data together with our findings may explain that Wallerian degeneration precedes oligodendrocyte stress and complement activation in the course of microglial nodule formation.

Microglial nodules were observed irrespective of disease duration in MS NAWM [46, 54]. One particular report studied 52 post-mortem MS cases and illustrated that the incidence of microglial nodules decreases with the increase in disease duration [46]. Given that most of the microglial/ macrophage clusters in MS were found to be present in close vicinity to demyelinated plaques [46, 52, 54], we considered a cohort of biopsied patients with median disease duration of 22.5 days ideal for studying microglial nodules close to disease onset. Our data, in contrast to prior studies based on autopsy material from chronic MS patients, found altered/ damaged axons associated with microglial nodules. Previous neuropathological findings addressing structural damage in MS lesions support the idea that the occurrence of microglial nodules in MS is reactive [6, 21, 29]. Stainings in the PPWMcontaining nodules appeared normal for all the given myelin markers, a finding that further rules out myelin abnormalities as the primary trigger $[46,54]$. This in turn also supports that myelin breakdown/clearance is a delayed and slow process in CNS Wallerian degeneration $[47,56]$. Neuroradiological observations showing an association of regional lesion load and axonal density in related NAWM suggest that the observed abnormalities in non-demyelinated white matter may have at least partly developed as a result of axonal transections within lesions [14, 20, 37, 59]. In line with this, the presence of NPY-Y1R ${ }^{+}$axons within the microglial nodules indicates that these nodules may have formed as outcome sequelae of Wallerian degeneration in PPWM caused by lesional pathology.
Indeed, microglial nodules are regularly seen in brain trauma [22], and in this study, supporting the earlier finding, we observed microglial nodules in the perilesional white matter of brain infarcts and TBI lesions but not in epilepsy and control cases. Also, in our previous study, we demonstrated high numbers of NPY-Y1 ${ }^{+}$degenerating axons in infarct tissue while axonal degeneration was virtually absent in epilepsy patients. This underlines that the microglial nodules in CNS white matter tend to occur in overt axonal degenerative conditions and therefore may develop in various brain disorders. Microglial nodule formation induced by anterograde axonal degeneration was also observed in mice, which further supports the notion that the event of nodule formation is driven by axonal degeneration in CNS white matter [16]. Recent magnetic resonance $7 \mathrm{~T} \mathrm{~T}_{2} *$ imaging studies revealed that MS white matter lesions are perivenous [17, 50]. Besides MS, acute disseminated encephalomyelitis (ADEM) and even experimental autoimmune encephalomyelitis (EAE) lesions are known to develop as a rule around a central vein(s) [28, 32, 60]. On this basis, it seems uncertain that the microglial nodules in MS can expand to form a new, full-blown demyelinating lesion involving a pathogenesis that excludes blood-brain barrier alterations. However, De Groot et al. [13] also described clusters of microglial/macrophage cells contiguous with blood vessels containing CD45-positive lymphocytes as (p)reactive; in this context, we did not find any microglial nodule directly linked with blood vessels in the present study [54].

Our results also suggest that mechanisms other than Wallerian degeneration may contribute to axonal damage associated with microglial nodules in MS. The association of $\mathrm{SMI}_{32}{ }^{+}$axons and frequent accumulation of $\mathrm{APP}^{+}$ axonal end bulbs with microglial nodules and the surrounding activated microglia/macrophages in MS white matter supports the hypothesis that microglial inflammation can have detrimental effects and mediate axonal damage [24, 30, 38, 41]. Previous reports demonstrated that inflammatory mediators secreted from activated microglia/ macrophages such as matrix metalloproteinases, proinflammatory cytokines, nitric oxide and reactive oxygen species may cause disruption of axoplasmic transport and axon integrity, eventually leading to axotomy $[4,15,39$, 40, 49]. Maeda and Sobel [34] detected matrix metalloproteinases activity, while van Horssen et al. [54] observed NADPH oxidase, TNF-alpha and IL-10 expression in MS microglial nodules. Interestingly, we observed strong CD40, iNOS and CD163 expression in these foci. This may explain the inconsistency in the occurrence of $\mathrm{APP}^{+}$axonal profiles in microglial nodules, i.e., that antiinflammatory mechanisms could possibly restrain the damage caused in response to focal microglia/macrophage activation. Despite this, we do not have a complete explanation for these 
phenotypes. However, the time factor following the trigger could play a decisive role, as the initial proinflammatory niche of activated microglia/macrophages appears to shift towards the antiinflammatory [8]. Yet, all the nodules studied contained SMI $32^{+}$profiles, which further suggests that the axons in PPWM/NAWM are more susceptible to altered patterns of phosphorylation of neurofilament proteins as compared to intra-axonal APP accumulation [19]. Another possible cause for $\mathrm{APP}^{+}$and $\mathrm{SMI}_{3}{ }^{+}$axonal structures detected in PPWM could be a direct anti-axonal immune response, e.g., anti-neurofascin antibodies, which selectively target neurofascin at the nodes of Ranvier in animal models and may subsequently lead to local microglia/macrophage activation [35].

In conclusion, the functional relationship between NPY$\mathrm{Y}_{1} \mathrm{R}^{+}$axons and microglial nodules observed in this study demonstrate that the process of axonal degeneration may cause microglial nodule formation, at least in early MS PPWM. In light of this, our data do not appear to concur with the notion that the pathogenesis of (p)reactive lesions is similar to other analogous MS lesions, such as pattern III lesions and newly forming lesions, both of which are clearly described in terms of oligodendrogliopathy and myelin loss [2,33]. Considering the fact that pathology can provide only a snapshot of an on-going course of action in the evolving disease, immune-regulatory phenotyping of such nodules in MS may reveal its overall significance in the disease.

Acknowledgments This work was supported by the DFG transregional collaborative research group (TRR-SFB) 43 "The brain as a target of inflammatory processes," the MS Society of Great Britain and Northern Ireland and Stichting MS Research, The Netherlands. S. Singh was supported by an Erasmus Mundus (ENC-Network) grant. We thank Brigitte Maruschak and Katja Schulz for expert technical assistance, Dr. Johannes Wessels for support with confocal microscopy as well as Sven Müller for excellent administrational help.

Open Access This article is distributed under the terms of the Creative Commons Attribution License which permits any use, distribution, and reproduction in any medium, provided the original author(s) and the source are credited.

\section{References}

1. Barnett MH, Parratt JD, Cho ES, Prineas JW (2009) Immunoglobulins and complement in postmortem multiple sclerosis tissue. Ann Neurol 65:32-46

2. Barnett MH, Prineas JW (2004) Relapsing and remitting multiple sclerosis: pathology of the newly forming lesion. Ann Neurol 55:458-468

3. Benveniste EN, Nguyen VT, Wesemann DR (2004) Molecular regulation of $\mathrm{CD} 40$ gene expression in macrophages and microglia. Brain Behav Immun 18(1):7-12
4. Bitsch A, da Costa C, Bunkowski S, Weber F, Rieckmann P, Brück W (1998) Identification of macrophage populations expressing tumor necrosis factor-a mRNA in acute multiple sclerosis. Acta Neuropathol 95:373-377

5. Bitsch A, Schuchardt J, Bunkowski S, Kuhlmann T, Brück W (2000) Acute axonal injury in multiple sclerosis. Correlation with demyelination and inflammation. Brain 123:1174-1183

6. Bjartmar C, Kinkel PR, Kidd G, Rudick RA, Trapp BD (2001) Axonal loss in normal-appearing white matter in a patient with acute MS. Neurology 57:1248-1252

7. Bordey A, Spencer DD (2003) Chemokine modulation of highconductance $\mathrm{Ca}(2+)$-sensitive $\mathrm{K}(+)$ currents in microglia from human hippocampi. Eur J Neurosci 18:2893-2898

8. Boven LA, Van Meurs M, Van Zwam M, Wierenga-Wolf A, Hintzen RQ, Boot RG, Aerts JM, Amor S, Nieuwenhuis EE, Laman JD (2006) Myelin-laden macrophages are anti-inflammatory, consistent with foam cells in multiple sclerosis. Brain 129:517-526

9. Brück W, Porada P, Poser S, Rieckmann P, Hanefeld F, Kretzschmar HA, Lassmann H (1995) Monocyte/macrophage differentiation in early multiple sclerosis lesions. Ann Neurol 38:788-796

10. Casanova B, Martinez-Bisbal MC, Valero C, Celda B, MartiBonmati L, Pascual A, Landente L, Coret F (2003) Evidence of Wallerian degeneration in normal appearing white matter in the early stages of relapsing-remitting multiple sclerosis. A ${ }^{1}$ HMRS study. J Neurol 250:22-28

11. Ciccarelli O, Werring DJ, Barker GJ, Griffin CM, WheelerKingshott CA, Miller DH, Thompson AJ (2003) A study of the mechanisms of normal-appearing white matter damage in multiple sclerosis using diffusion tensor imaging. Evidence of Wallerian degeneration. J Neurol 250:287-292

12. Corness J, Shi TJ, Xu ZQ, Brulet P, Hökfelt T (1996) Influence of leukemia inhibitory factor on galanin/GMAP and neuropeptide $\mathrm{Y}$ expression in mouse primary sensory neurons after axotomy. Exp Brain Res 112(1):79-88

13. De Groot CJA, Bergers E, Kamphorst W, Ravid R, Polman CH, Barkhof F, van der Valk P (2001) Post-mortem MRI-guided sampling of multiple sclerosis brain lesions. Increased yield of active demyelinating and (p)reactive lesions. Brain 124:1635-1645

14. De Stefano N, Narayanan S, Matthews PM, Francis GS, Antel JP, Arnold DL (1999) In vivo evidence for axonal dysfunction remote from focal cerebral demyelination of the type seen in multiple sclerosis. Brain 122:1933-1939

15. Dheen S, Kaur C, Ling E (2007) Microglial activation and its implications in the brain diseases. Curr Med Chem 14(11): 1189-1197

16. Dissing-Olesen L, Ladeby R, Nielsen HH, Toft-Hansen H, Dalmau I, Finsen B (2007) Axonal lesion-induced microglial proliferation and microglial cluster formation in the mouse. Neuroscience 149:112-122

17. Dixon JE, Simpson A, Mistry N, Evangelou N, Morris PG (2011) Optimisation of T(2)(*)-weighted MRI for the detection of small veins in multiple sclerosis at 3T and 7T. Eur J Radiol epub Eur J Radiol (Epub ahead of print 02 December 2011). doi: 10.1016/ j.ejrad.2011.09.023

18. Dutta R, Trapp BD (2007) Pathogenesis of axonal and neuronal damage in multiple sclerosis. Neurology 68:S22-S31

19. Dziedzic T, Metz I, Dallenga T, Konig FB, Muller S, Stadelmann C, Brück W (2010) Wallerian degeneration: a major component of early axonal pathology in multiple sclerosis. Brain Pathol 20:976-985

20. Evangelou N, Esiri MM, Smith S, Palace J, Matthews PM (2000) Quantitative pathological evidence for axonal loss in normal appearing white matter in multiple sclerosis. Ann Neurol 47:391-395 
21. Ferguson B, Matyszak MK, Esiri MM, Perry VH (1997) Axonal damage in acute multiple sclerosis lesions. Brain 120:393-399

22. Geddes JF (2005) Primary traumatic brain injury. In: Whitwell HL, Arnold E (eds) Forensic neuropathology, p 95-106

23. Gordon S (2003) Alternative activation of macrophages. Nat Rev Immunol 3(1):23-35

24. Howell OW, Rundle JL, Garg A, Komada M, Brophy PJ, Reynolds R (2010) Activated microglia mediate axoglial disruption that contributes to axonal injury in multiple sclerosis. J Neuropathol Exp Neurol 69:1017-1033

25. Huizinga R, van der Star BJ, Kipp M, Jong R, Gerritsen W, Clarner T, Puentes F, Dijkstra CD, van der Valk P, Amor S (2012) Phagocytosis of neuronal debris by microglia is associated with neuronal damage in multiple sclerosis. Glia 60(3):422-431

26. Komohara Y, Hirahara J, Horikawa T, Kawamura K, Kiyota E, Sakashita N, Araki N, Takeya M (2006) AM-3 K, an anti-macrophage antibody, recognizes CD163, a molecule associated with an anti-inflammatory macrophage phenotype. J Histochem Cytochem 54(7):763-771

27. Kreutzberg GW (1996) Microglia: a sensor for pathological events in the CNS. Trends Neurosci 19:312-318

28. Kuhlmann T, Lassmann H, Brück W (2008) Diagnosis of inflammatory demyelination in biopsy specimens: a practical approach. Acta Neuropathol 115(3):275-287

29. Kuhlmann T, Lingfeld G, Bitsch A, Schuchardt J, Brück W (2002) Acute axonal damage in multiple sclerosis is most extensive in early disease stages and decreases over time. Brain 125:2202-2212

30. Kutzelnigg A, Lucchinetti CF, Stadelmann C, Brück W, Rauschka H, Bergmann M, Schmidbauer M, Parisi JE, Lassmann H (2005) Cortical demyelination and diffuse white matter injury in multiple sclerosis. Brain 128:2705-2712

31. Lassmann H (1998) Pathology of multiple sclerosis. In: Compston A, Ebers G, Lassmann H, McDonald I, Matthews B, Wekerle $\mathrm{H}$ (eds) McAlpine's multiple sclerosis. Churchill Livingstone, London, pp 323-358

32. Lassmann H, Kitz K, Wisniewski HM (1980) Structural variability of demyelinating lesions in different models of subacute and chronic experimental allergic encephalomyelitis. Acta Neuropathol 51:191-201

33. Lucchinetti C, Brück W, Parisi J, Scheithauer B, Rodriguez M, Lassmann H (2000) Heterogeneity of multiple sclerosis lesions: implications for the pathogenesis of demyelination. Ann Neurol 47:707-717

34. Maeda A, Sobel RA (1996) Matrix metalloproteinases in the normal human central nervous system, microglial nodules, and multiple sclerosis lesions. J Neuropathol Exp Neurol 55:300-309

35. Mathey EK, Derfuss T, Storch MK, Williams KR, Hales K, Woolley DR, Al-Hayani A, Davies SN, Rasband MN, Olsson T, Moldenhauer A, Velhin S, Hohlfeld R, Meinl E, Linington C (2007) Neurofascin as a novel target for autoantibody-mediated axonal injury. J Exp Med 204:2363-2372

36. McDonald WI, Compston A, Edan G, Goodkin D, Hartung HP, Lublin FD, McFarland HF, Paty DW, Polman CH, Reingold SC, Sandberg-Wollheim M, Sibley W, Thompson A, van den Noort S, Weinshenker BY, Wolinsky JS (2001) Recommended diagnostic criteria for multiple sclerosis: guidelines from the International Panel on the diagnosis of multiple sclerosis. Ann Neurol 50(1):121-127

37. Moll NM, Rietsch AM, Thomas S, Ransohoff AJ, Lee JC, Fox R, Chang A, Ransohoff RM, Fisher E (2011) Multiple sclerosis normal-appearing white matter: pathology-imaging correlations. Ann Neurol 70:764-773

38. Moreno B, Jukes JP, Vergara-Irigaray N, Errea O, Villoslada P, Perry VH, Newman TA (2011) Systemic inflammation induces axon injury during brain inflammation. Ann Neurol. 70:932-942
39. Newman TA, Woolley ST, Hughes PM, Sibson NR, Anthony DC, Perry VH (2001) T-cell- and macrophage-mediated axon damage in the absence of a CNS-specific immune response: involvement of metalloproteinases. Brain 124:2203-2214

40. Nikic I, Merkler D, Sorbara C, Brinkoetter M, Kreutzfeldt M, Bareyre FM, Brück W, Bishop D, Misgeld T, Kerschensteiner M (2011) A reversible form of axon damage in experimental autoimmune encephalomyelitis and multiple sclerosis. Nat Med 17:495-499

41. Palin K, Cunningham C, Forse P, Perry VH, Platt N (2008) Systemic inflammation switches the inflammatory cytokine profile in CNS Wallerian degeneration. Neurobiol Dis 30:19-29

42. Pesini P, Kopp J, Wong H, Walsh JH, Grant G, Hökfelt T (1999) An immunohistochemical marker for Wallerian degeneration of fibers in the central and peripheral nervous system. Brain Res 828:41-59

43. Poser CM, Paty DW, Scheinberg L, McDonald WI, Davis FA, Ebers GC, Johnson KP, Sibley WA, Silberberg DH, Tourtellotte WW (1983) New diagnostic criteria for multiple sclerosis: guidelines for research protocols. Ann Neurol 13(3):227-231

44. Prineas JW (1985) The neuropathology of multiple sclerosis. In: Vinken PJ, Bruyn GW, Klawans HL (eds) Handbook of clinical neurology. Elsevier Sciences, Amsterdam, pp 213-257

45. Prineas JW, Kwon EE, Cho ES, Sharer LR, Barnett MH, Oleszak EL, Hoffman B, Morgan BP (2001) Immunopathology of secondary-progressive multiple sclerosis. Ann Neurol 50:646-657

46. Sanders V, Conrad AJ, Tourtellotte WW (1993) On classification of post-mortem multiple sclerosis plaques for neuroscientists. J Neuroimmunol 46:207-216

47. Shi F, Zhu H, Yang S, Liu Y, Feng Y, Shi J, Xu D, Wu W, You S, Ma Z, Zou J, Lu P, Xu XM (2009) Glial response and myelin clearance in areas of Wallerian degeneration after spinal cord hemisection in the monkey Macaca fascicularis. J Neurotrauma 26(11):2083-2096

48. Simon JH, Kinkel PR, Jacobs L, Bub L, Simonian N (2000) A Wallerian degeneration pattern in patients at risk for MS. Neurology 54:1155-1160

49. Smith KJ, Lassmann H (2002) The role of nitric oxide in multiple sclerosis. Lancet Neurol 1:232-241

50. Tallantyre EC, Morgan PS, Dixon JE, Al-Radaideh A, Brookes MJ, Evangelou N, Morris PG (2009) A comparison of 3T and 7T in the detection of small parenchymal veins within MS lesions. Invest Radiol 44:491-494

51. Thompson AJ, Montalban X, Barkhof F, Brochet B, Filippi M, Miller DH, Polman CH, Stevenson VL, McDonald WI (2000) Diagnostic criteria for primary progressive multiple sclerosis: a position paper. Ann Neurol. 47(6):831-835

52. van der Valk P, De Groot CJA (2000) Review. Staging of multiple sclerosis (MS) lesions: pathology of the time frame of MS. Neuropathol Appl Neurobiol 26:2-10

53. van der Valk P, Amor S (2009) Preactive lesions in multiple sclerosis. Curr Opin Neurol 22:207-213

54. van Horssen J, Singh S, van der Pol S, Kipp M, Lim JL, Peferoen L, Gerritsen W, Kooi EJ, Witte ME, Geurts JJ, de Vries HE, Peferoen-Baert R, van den Elsen PJ, van der Valk P, Amor S (2012) Clusters of activated microglia in normal-appearing white matter show signs of innate immune activation. J Neuroinflammation 9(1):156

55. van Noort JM, Bsibsi M, Gerritsen WH, Van der Valk P, Bajramovic JJ, Steinman L, Amor S (2010) Alphab-crystallin is a target for adaptive immune responses and a trigger of innate responses in preactive multiple sclerosis lesions. J Neuropathol Exp Neurol 69:694-703

56. Vargas ME, Barres BA (2007) Why is Wallerian degeneration in the CNS so slow? Annu Rev Neurosci 30:153-179

57. Wakisaka S, Kajander KC, Bennett GJ (1991) Increased neuropeptide Y (NPY)-like immunoreactivity in rat sensory neurons following peripheral axotomy. Neurosci Lett 124(2):200-203 
58. Wakisaka S, Kajander KC, Bennett GJ (1992) Effects of peripheral nerve injuries and tissue inflammation on the levels of neuropeptide Y-like immunoreactivity in rat primary afferent neurons. Brain Res 598(1-2):349-352

59. Werring DJ, Brassat D, Droogan AG, Clark CA, Symms MR, Barker GJ, MacManus DG, Thompson AJ, Miller DH (2000) The pathogenesis of lesions and normal-appearing white matter changes in multiple sclerosis. A serial diffusion MRI study. Brain 123:1667-1676

60. Young NP, Weinshenker BG, Parisi JE, Scheithauer B, Giannini C, Roemer SF, Thomsen KM, Mandrekar JN, Erickson BJ, Lucchinetti CF (2010) Perivenous demyelination: association with clinically defined acute disseminated encephalomyelitis and comparison with pathologically confirmed multiple sclerosis. Brain 133:333-348

61. Zhang X, Bao L, Xu ZQ, Kopp J, Arvidsson U, Elde R, Hökfelt T (1994) Localization of neuropeptide Y Y1 receptors in the rat nervous system with special reference to somatic receptors on small dorsal root ganglion neurons. Proc Natl Acad Sci USA 91(24):11738-11742

62. Zhang Z, Zhang ZY, Schittenhelm J, Wu Y, Meyermann R, Schluesener HJ (2011) Parenchymal accumulation of CD163 + macrophages/microglia in multiple sclerosis brains. J Neuroimmunol 237:73-79 